\title{
A conservation assessment of the terrestrial invertebrate fauna of Mkambati Nature Reserve in the Pondoland Centre of Endemism
}

\begin{tabular}{|c|c|}
\hline \multicolumn{2}{|c|}{$\begin{array}{l}\text { Authors: } \\
\text { Michelle L. Hamer }{ }^{1,2} \\
\text { Rob Slotow }\end{array}$} \\
\hline \multicolumn{2}{|c|}{$\begin{array}{l}\text { Affiliations: } \\
{ }^{1} \text { Zoological Systematics \& } \\
\text { Research Collections, South } \\
\text { African National Biodiversity } \\
\text { Institute, South Africa }\end{array}$} \\
\hline $\begin{array}{l}{ }^{2} \text { School of Life } \\
\text { University of } \\
\text { South Africa }\end{array}$ & $\begin{array}{l}\text { Sciences, } \\
\text { waZulu-Natal, }\end{array}$ \\
\hline \multicolumn{2}{|c|}{$\begin{array}{l}{ }^{3} \text { School of Genetics, Evolution } \\
\text { and Environment, University } \\
\text { College, United Kingdom }\end{array}$} \\
\hline \multicolumn{2}{|c|}{$\begin{array}{l}\text { Corresponding author: } \\
\text { Michelle Hamer, } \\
\text { m.hamer@sanbi.org.za }\end{array}$} \\
\hline \multicolumn{2}{|c|}{$\begin{array}{l}\text { Dates: } \\
\text { Received: } 29 \text { July } 2016 \\
\text { Accepted: } 02 \text { Feb. } 2017 \\
\text { Published: } 04 \text { May } 2017\end{array}$} \\
\hline \multicolumn{2}{|c|}{$\begin{array}{l}\text { How to cite this article: } \\
\text { Hamer, M.L. \& Slotow, R., } \\
\text { 2017, 'A conservation } \\
\text { assessment of the terrestrial } \\
\text { invertebrate fauna of } \\
\text { Mkambati Nature Reserve in } \\
\text { the Pondoland Centre of } \\
\text { Endemism', Koedoe 59(1), } \\
\text { a1428. https://doi. } \\
\text { org/10.4102/koedoe. } \\
\text { v59i1.1428 }\end{array}$} \\
\hline \multicolumn{2}{|c|}{$\begin{array}{l}\text { Copyright: } \\
\text { (C) 2017. The Authors, } \\
\text { Licensee: AOSIS. This } \\
\text { is licensed under the } \\
\text { Creative Commons } \\
\text { Attribution License. }\end{array}$} \\
\hline \multicolumn{2}{|l|}{ Read online: } \\
\hline 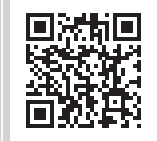 & $\begin{array}{l}\text { Scan this QR } \\
\text { code with your } \\
\text { smart phone or } \\
\text { mobile device } \\
\text { to read online. }\end{array}$ \\
\hline
\end{tabular}

Mkambati Nature Reserve (NR) falls within the Pondoland Centre of Endemism, which is part of the Maputaland-Pondoland-Albany global biodiversity hotspot. The biodiversity status of this area is based largely on its flora, and the invertebrates are poorly known. The area is under threat from various proposed developments. We surveyed 14 orders in three invertebrate phyla at 26 sites with two main objectives: (1) to assess the fauna in terms of conservation value, and, (2) to identify habitats and sites of conservation concern. From the survey, 3231 samples were sent for identification and 425 species were identified. A minimum of 18 new species were confirmed. Mkambati NR shows exceptional diversity for molluscs (Gastropoda, 51 species), bees (Apoidea, 48 species) and true bugs (Heteroptera, 65 species). At least 43 species collected from the Reserve are South African endemics, 31 have a restricted distribution within South Africa and 18 are only known from the Reserve itself.

Conservation implications: The authors provide the first assessment of the invertebrate fauna of the Mkambati NR, which indicates that it is a rich and important fauna. The results highlight the need to consider invertebrates in other biodiversity assessments in the Pondoland region. In terms of habitats, for both forest and grassland there was a large difference in the invertebrate communities at different sites, even over relatively short distances in grassland; shared habitat attributes clustered sites with more similar communities, for example, rocky ledges or the sea shore. All forest patches are a priority for protection.

\section{Introduction}

Biodiversity inventories are essential for planning, managing and monitoring activities, including in protected areas. Surveys and inventories are considered by conservationists as being good investments (Balmford \& Gaston 1999; Rohr, Mahan \& Kim 2006). They are essential to determining the level and patterns of diversity within an area (Deharveng et al. 2015), including the identities and number of taxa, their distribution and the diversity of communities.

Invertebrates are a major component of biodiversity. They are important in all ecosystems in terms of species richness (an estimated 95\% of all species are invertebrates [Myers et al. 2000]), abundance and biomass, and they play vital roles in processes such as pollination, soil formation and fertility, plant productivity, organic decomposition and the regulation of populations of other organisms. Invertebrates are also part of nearly every food chain, and they are a food source for many vertebrates (Kellert 1993). Losey and Vaughan (2006) estimated that the annual financial benefit of insects through just four ecosystem services (pollination, dung burial, control of native herbivores and ecotourism) in the United States alone added up to $\$ 57$ billion per annum. However, the positive role of invertebrates in ecosystems was not considered in the Millennium Assessment or the Intergovernmental Panel on Climate Change (Prather et al. 2013), and they are generally not represented in inventories nor are they considered in local-scale conservation or management activities (McGeoch et al. 2011). In addition to their functional roles, many invertebrate taxa have small distribution ranges, that is, they are narrow endemics (Harvey 2002), and they are therefore of conservation importance. Invertebrates are also recognised as being important indicators of environmental condition or change (Hodkinson \& Jackson 2005; McGeoch et al. 2011; Paoletti, Thomson \& Hoffmann 2007).

There are a number of reasons for the lack of inclusion of invertebrates in conservation and management activities. Cardoso et al. (2011) listed seven main constraints for invertebrate conservation, including a lack of awareness of the ecological role of invertebrates among the

Note: Additional supporting information may be found in the online version of this article as Online Appendix 1: https://doi.org/10.4102/ koedoe.v59i1.1428-1 
public and decision-makers, lack of basic scientific knowledge, including changes in abundance in space and time, way of life and sensitivity of species to habitat change, a large number of undescribed species and poor knowledge about the distribution of known species. The authors suggested mainly high-level and longer term solutions, but they did include provision of funds for inventories, and the use of repeatable sampling methods for surveys in their suggestions.

The Maputaland-Pondoland-Albany (MPA) is one of 34 recognised global biodiversity hotspots (Mittermeier et al. 2004) and one of three that are represented in South Africa. The Pondoland region of the Eastern Cape coastal area is recognised as a centre of high plant diversity and endemism (Van Wyk \& Smith 2001) with over 200 endemic plant species. An analysis of the vertebrate fauna of the broader MPA has been carried out (Perera, Ratnayake-Perera \& Proches 2011) and identified two endemic reptile species in the Pondoland coastal forests. A herpetological survey of the protected areas of the Wild Coast part of the Eastern Cape, which includes Pondoland, resulted in a list of 22 amphibian and 37 reptile species (Venter \& Conradie 2015). The invertebrate fauna of Pondoland are very poorly studied. Existing information comprises one survey of the herbivorous insect species associated with 12 tree species in a forest patch (Moran et al. 1994) and one publication on the spider fauna of Mkambati Nature Reserve (NR) which resulted from the study presented here (Dippenaar-Schoeman, Hamer \& Haddad 2011). There are published records of individual species or taxa that are in taxonomic revisions or descriptions, and there are specimens in collections, but these data are scattered through museums or in various, often difficult to access, publications. No multitaxa, quantified survey of invertebrates has previously been carried out in Pondoland. Quantified surveys are critical for comparison of areas and for providing future baseline data for monitoring (Lovell et al. 2010; Slotow \& Hamer 2000).

Mkambati NR falls within the Pondoland area and was selected for the survey of invertebrates because of proposals for expanding tourism development in the Reserve, the proposed construction of a major highway adjacent to the Reserve, the threat of dune mining in the region, and because of management concerns about frequent fires in some grassland areas. This study provides the first multi-taxa assessment of invertebrates of the Reserve, but it will also have relevance for and application to conservation in the surrounding Pondoland region. The two objectives of the study were (1) to assess the fauna in terms of diversity, level of knowledge (new species) and conservation value (endemic species and threatened species) and (2) to identify sites and habitats of high value for invertebrate conservation. We recognise that the extent of the survey may be limited in terms of sampling completeness especially considering likely temporal changes in invertebrate communities (Janzen 1973; Lovell et al. 2010), but the resources (capacity, time and funding) to process and identify the number of samples that would be required to achieve sampling completeness are extensive (Deharveng et al. 2015; Lovell et al. 2010). The results presented here should be seen in the context of a snapshot sample of the invertebrates of a threatened and neglected part of a global biodiversity hotspot and centre of endemism, and also as a data set that can contribute to decision-making for the Reserve and for future monitoring programmes.

\section{Materials and methods Study site}

Mkambati NR (7720 ha) is situated on the north Eastern Cape coast between the Mtentu and Msikaba Rivers $\left(31^{\circ} 13^{\prime}-31^{\circ} 20^{\prime} \mathrm{S} / 29^{\circ} 55^{\prime}-30^{\circ} 04^{\prime} \mathrm{E}\right.$ ) (Figure 1), and it comprises mainly open grasslands dominated by fire-prone PondolandUgu Sandstone Coastal Sourveld (CB 4 in Mucina et al. 2006), with patches of scarp (FOz5) and swamp forest (FOa 2) (Mucina \& Geldenhuys 2006; Mucina et al. 2006). The climate is subtropical, with summer rainfall that averages over $1000 \mathrm{~mm}$ per annum. The geology is predominantly Pondoland or Natal sandstone, of the Msikaba Formation. Details of geology and climate for the Reserve are provided by Shackleton et al. (1991).

Mkambati was a leper colony from 1922 to 1976 (Kepe 2004) with restricted access by local communities who had been removed from the area. In 1976, the leper colony was closed down, and in 1977, part of the land was declared a state protected area. Since the early 1990s, access by the communities to the resources within the Reserve has been permitted (Kepe 2004), and after a protracted process, a land claim by the original inhabitants of the area was approved, which restored ownership to the community. There are, however, several restrictions associated with the title deeds, including that the Mkambati NR must remain a protected area in perpetuity and that it may not be used for residential purposes (Kepe 2008). The Reserve is currently managed by Eastern Cape Parks and Tourism.

\section{Sampling sites}

We surveyed Mkambati NR between 24 January 2008 and 03 February 2008. The survey team comprised two invertebrate researchers and five research assistants, as well as seven volunteers recruited through the Earthwatch Institute, and a scientist from Eastern Cape Parks and Tourism. We sampled a total of 26 sites (details provided in Figure 2) that included six forest patches, representing scarp and swamp forest, and 20 grassland sites, covering sites from the coast at $16 \mathrm{~m}$ a.s.l., those near wetlands, on rocky hills or slopes, and sites inland at $311 \mathrm{~m}$ a.s.l. (Figures 1 and 3). Additional photographs of selected sites were presented in Dippenaar et al. (2011).

\section{Target taxa}

Not all invertebrates were targeted for inclusion in the survey because of the enormous diversity and abundance of invertebrates, and the implications of this for capacity, time and funds required for processing and identifying material to species level. We selected invertebrates for which expertise to identify material exists, and that would represent a range of functional roles (predators, herbivores and detritivores), 


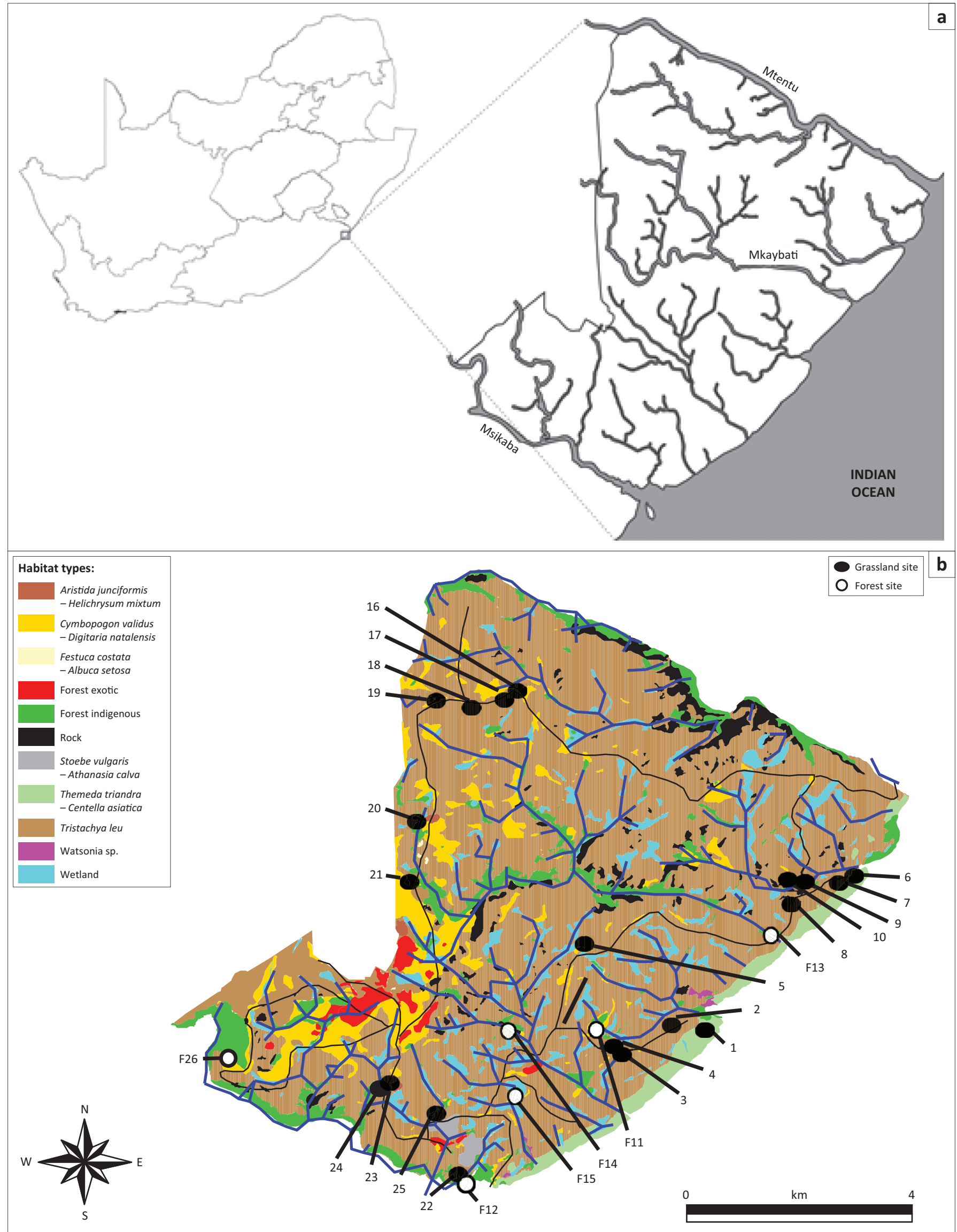

Source: Map (a) from Dippenaar-Schoeman et al. (2011) and map (b) modified from Shackleton et al. (1991)

FIGURE 1: (a) South Africa showing position of Mkambati Nature Reserve and map of Mkambati NR showing rivers and boundaries and (b) map showing vegetation types and location of the forest and grassland sampling sites. 


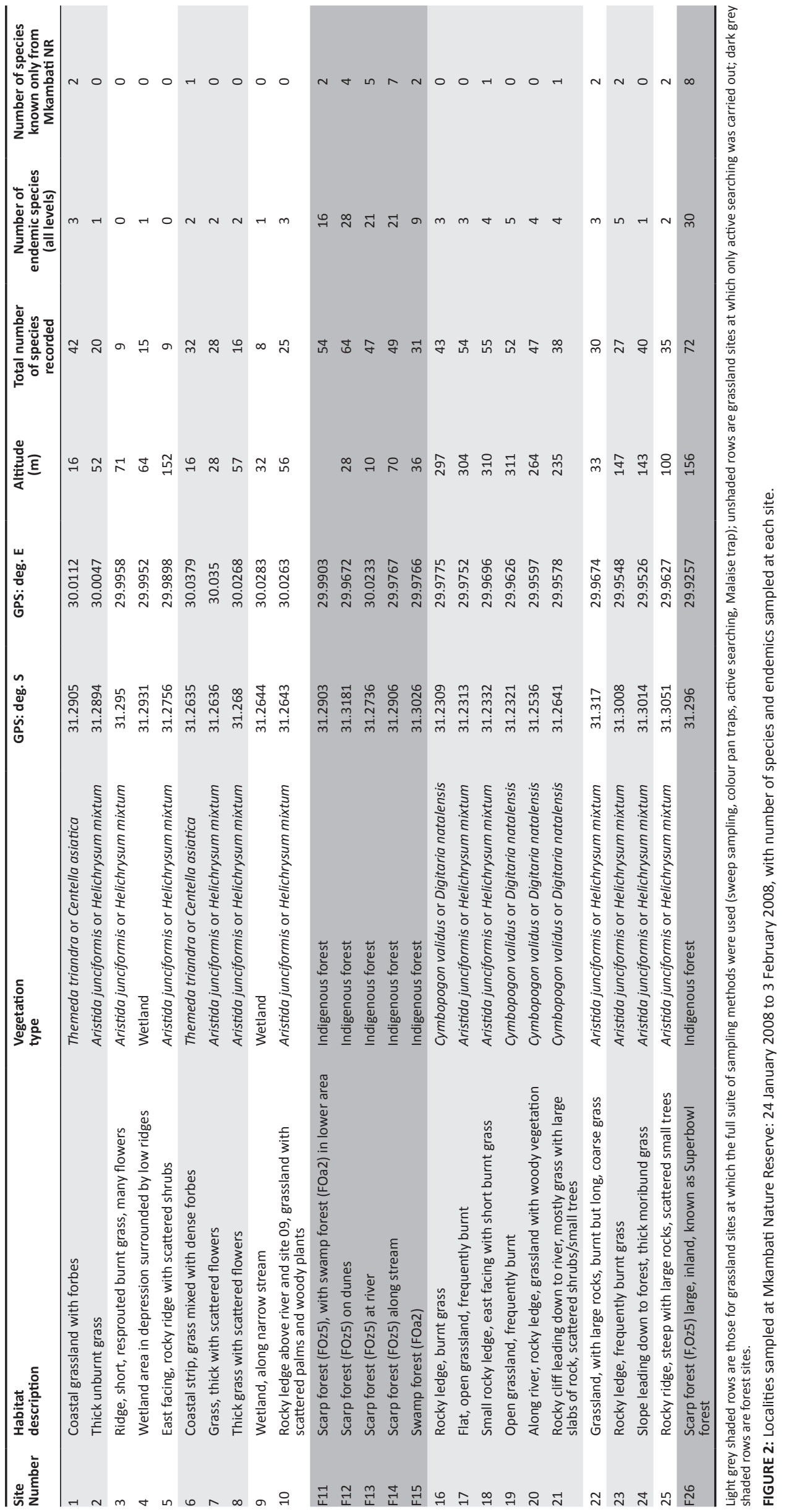




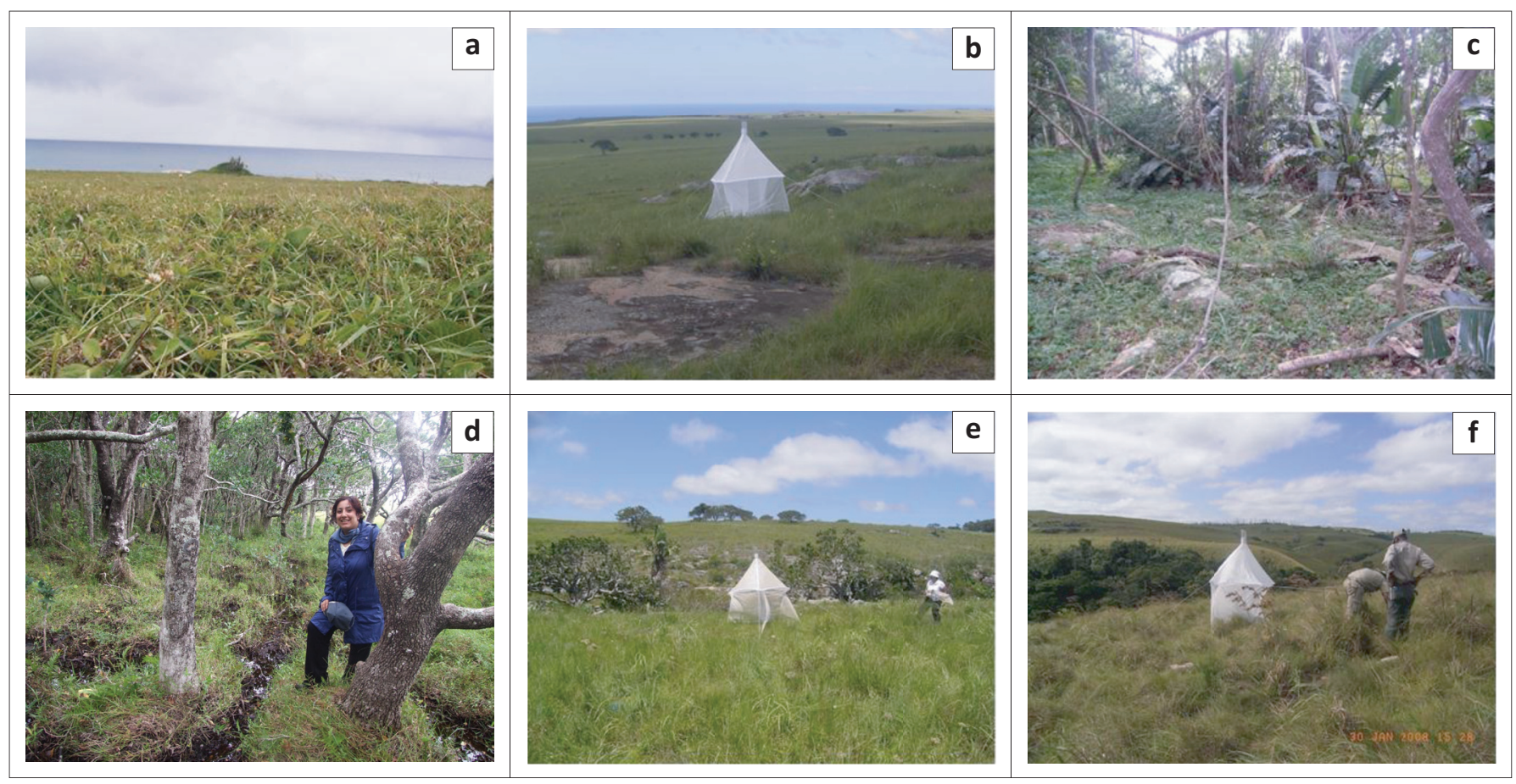

Source: Photos taken by M.L. Hamer, L. Stone and R. Slotow

FIGURE 3: Selected sampling sites at Mkambati Nature Reserve. (a) Site 6, (b) site 16, (c) site F11, (d) site F15, (e) site 20 and (f) site 24.

mobilities, body sizes and life histories. In forests, the focus was on ground-dwelling invertebrates such as Gastropoda, Chilopoda, Diplopoda, Opilionida and Oligochaeta because narrow endemism of these taxa was expected to be higher in fragmented habitats (Harvey 2002). Other taxa (Araneae, Odonata, Heteroptera, Carabidae, Cicindellidae, Cetoniinae, Scarabaeinae, Neuroptera, Lepidoptera [butterflies only], Asilidae, Platystomatidae, Syrphidae and Apoideae) were sampled in both forest and grassland habitats.

\section{Sampling methods}

A variety of sampling methods were used because these target different microhabitats and taxa. The methods are effective and efficient and can be implemented by non-specialists, and they do not have a major impact on the environment (Deharveng et al. 2015; Lovell et al. 2010).

\section{Grassland sampling}

Twenty grassland sites, each covering approximately 1 ha and at least $200 \mathrm{~m}$ apart, were sampled. Sampling at each site included setting a Malaise trap at the centre of the site and five each of yellow, blue and white pan traps. These were filled with soapy water and placed on the ground $10 \mathrm{~m}$ apart. The traps were collected after 5 days, of which at least three were sunny. Six sweep samples, each comprising 40 sweeps with a net along a 50-m strip, with each sweep approximately $1 \mathrm{~m}$ apart, were taken from selected sites (Figure 2). The sweep samples were collected at least $50 \mathrm{~m}$ away from the colour pan and Malaise traps. Active searching for invertebrates on 40 flowers and with a net to sample flying insects for a total of $3 \mathrm{~h}$ per site was carried out at all 20 grassland sites (Figure 2). The flower sampling attempted to cover all the obvious plant species at the site and to spread the samples across the entire site area. The active searching was only performed in the morning between 09:00 and 12:00 on days when there was sunshine and minimum wind.

\section{Forest sampling}

Six forests, ranging in area from 30 ha to 640 ha and classified as scarp (either along a river or on a sand dune) or swamp forest, were sampled. We sampled two to four (depending on forest size) $20 \mathrm{~m} \times 20 \mathrm{~m}$ plots for $1 \mathrm{~h}$ each, with three people searching for $20 \mathrm{~min}$ in each plot, and thoroughly searched a $10 \mathrm{~m} \times 2 \mathrm{~m}$ quadrat divided into five contiguous $2 \mathrm{~m} \times 2 \mathrm{~m}$ blocks, with one person searching each block. Four leaf litter samples, each comprising a 2-1 bag of litter and the surface layer of soil, were collected from each forest to sample micromolluscs. Ten trees were each beaten 10 times by hitting a branch with a large, robust truncheon to sample selected invertebrate taxa. A cloth or beating tray was placed under the branch being beaten, and target invertebrates were collected from the cloth or tray using an aspirator or vial. Six fruit-baited butterfly traps were hung from trees in each of the forests and left for 2-5 days to collect butterflies, flies and fruit chafer beetles that were attracted by the rotting fruit bait. The traps could not be left for the same period of time in all of the forests because a limited number of traps were available for the study. This may have impacted the results.

Additional specimens were collected opportunistically outside the sampling sites. These 11 species are included in the checklist (Online Appendix 1), and in the species and specimen totals, but were excluded from the analyses. 


\section{Sample processing and identification}

For active sampling methods, where accurate identification in the field was possible, a maximum of five individuals were collected, and additional specimens were recorded and released. This was especially important in the case of long-lived taxa such as millipedes and large molluscs. For collected material, each sample, or specimen where these were separate, was labelled with a unique numeric code in the field. In the laboratory, mixed samples such as Malaise traps, pan traps and sweep samples were sorted to separate out each of the target taxa. Each target taxon was then separated into morphospecies, which were sent to experts for identification. Where identification lower than family was not possible, these records were removed from the data. In cases where the genus could be identified and species could be separated by the taxonomist but not named (morphospecies), we included these records in the data set. Specimens from the survey have been deposited into the Agricultural Research Council (ARC) National Collections, the KwaZulu-Natal Museum and the Ditsong National Museum of Natural History in Pretoria.

For micromolluscs, the leaf litter samples were air dried for approximately 1 week and sifted through a series of four sieves of decreasing mesh sizes. The four fragments from each sample were then searched using a dissecting microscope, and micromolluscs were removed by hand.

\section{Data analysis}

Sampling completeness was determined using EstimateS (Version 9.1.0), Copyright R. K. Colwell: http://purl.oclc. org/estimates, and has been plotted separately for forests and grassland.

Level of endemism could only be determined where comprehensive distribution data sets are available (e.g. The South African National Survey of Arachnida or ARC spider database), or where there are checklists (e.g. Hamer [1999] for millipedes), conservation assessments such as that for butterflies (Mecenero et al. 2013), or field guides that give species' distributions (Tarboton \& Tarboton [2002, 2005] for Odonata, Herbert \& Kilburn [2004] for terrestrial molluscs). The following categories of endemism were slightly modified from those described by Hamer and Slotow (2002): (1) national endemic = confined to South Africa, (2) regional endemic $=$ confined to an area where the two furthest locality points are between $60 \mathrm{~km}$ and $330 \mathrm{~km}$ apart, (3) local endemic - multiple localities known = more than one locality known and confined to an area where the two furthest points are less than $60 \mathrm{~km}$ apart and (4) known only from Mkambati NR.

We assessed differences in communities across sites and related these to the vegetation characteristics of the site. We analysed the grassland and forest sites separately, and to assess species assemblages sampled at each site, we constructed Bray-Curtis similarity matrices (presenceabsence), followed by analysis of similarity (ANOSIM) and non-metric multi-dimensional scaling (MDS) plots using PRIMER Version 5.2.9 (Clarke \& Warwick 2001). The BrayCurtis calculated on presence-absence data in PRIMER provides the same outcome as Jaccard and Sørensen, which are the two commonly used measures of similarity for this type of data (Clarke \& Gorley 2001). From ANOSIM, if $R>$ 0.75 , groups are well separated; if $R>0.5$, groups are overlapping but clearly different; if $R<0.25$, groups are barely separable (Clarke \& Gorley 2001). Only those grassland sites for which the full suite of sampling methods had been used (Figure 2) were included in these analyses, that is, effort was equal across sites.

\section{Results}

\section{Assessment of diversity or species richness}

A total of 2531 samples were sent for expert identification. Of these, 71 could not be identified to any useful level for various reasons. For some taxa, notably the millipedes (Diplopoda) and earthworms (Oligochaeta), a large proportion of the specimens were juveniles that could not be identified even to genus level. For other taxa such as the true bugs (Heteroptera), a large number of specimens could not be identified to species level because the expertise or taxonomic information does not currently exist. A total of 425 species were identified from the target taxa during the survey, with 211 from grassland, 155 from forest, 46 that were sampled in both biomes and 11 species without habitat details from opportunistic collecting. Sampling was not complete (Figure 4). The Chao 2 values calculated were $270.11 \pm 35.06 \mathrm{SD}$ species for forests and $373.64 \pm 39.8 \mathrm{SD}$ species for grassland, which suggests that approximately $74 \%$ of forest and $69 \%$ of grassland species present were actually sampled. One exotic earthworm was recorded from the forest biome. An annotated checklist of taxa sampled is presented as Online Appendix 1. This list excludes the spiders, which were published separately in Dippenaar et al. (2011).

The number of new species identified is a minimum of 18, with the possibility of this number being as high as 40 species (Table 1). The uncertainty in the figure is based on the need for DNA analysis in some cases, or the need for taxonomic revision or more specialist expertise to verify suspected new species.

Mkambati NR shows exceptional richness for some taxa, such as the molluscs (Gastropoda) (51 species), bees (Apoidea) (48 species) and true bugs (Hemiptera) (65 species). The bee and true bug richness is likely to be higher if sampling was repeated at different times of the year, but the molluscs do not show much temporal turnover (Uys, Hamer \& Slotow 2010), and the richness value for molluscs is unlikely to increase much with additional sampling.

The total number of endemics, at 104 species $(25 \%$ of the total number of species identified) (Table 2) that are endemic 

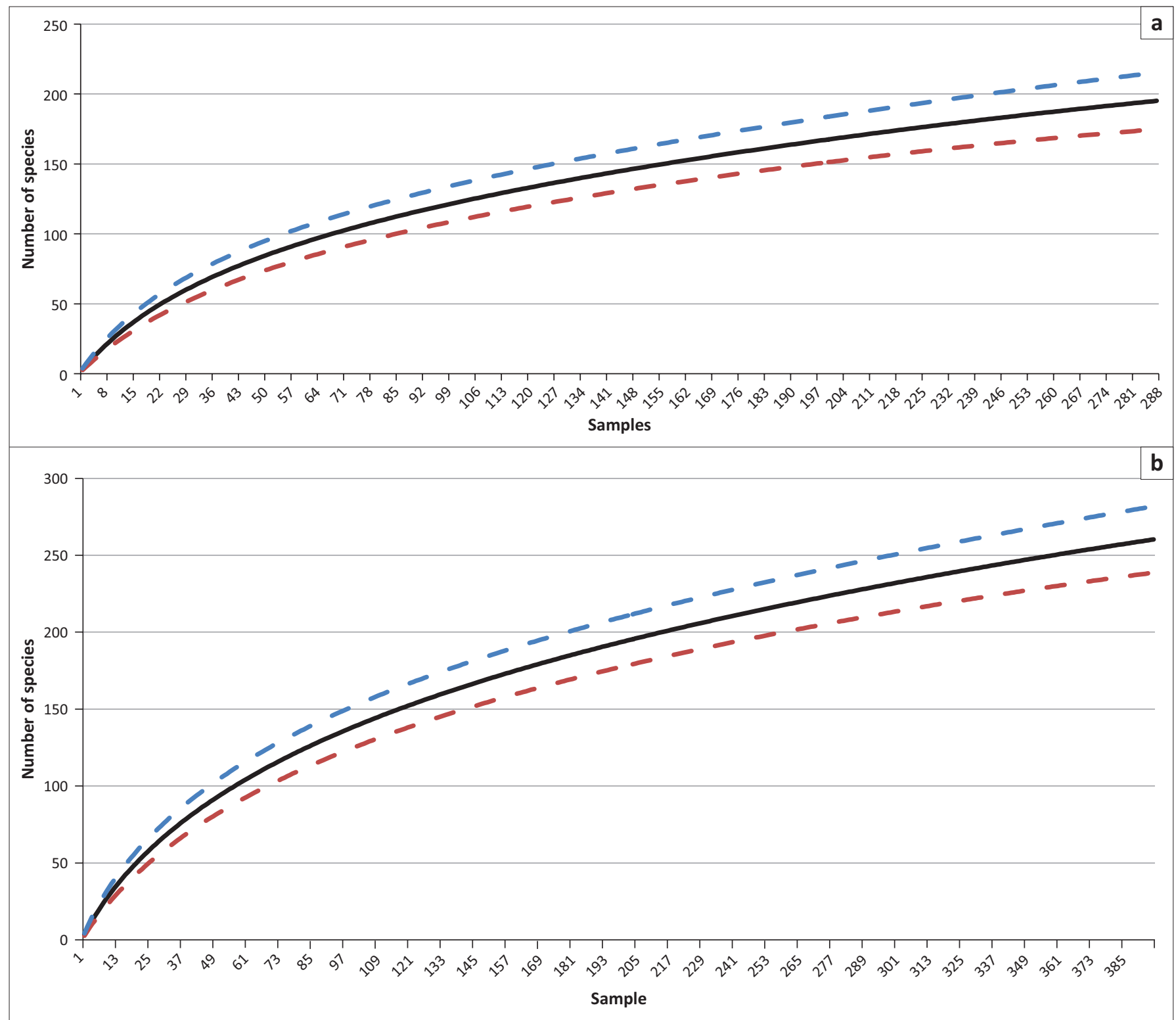

FIGURE 4: Species accumulation curves for (a) forest and (b) grassland sites at Mkambati Nature Reserve, calculated based on samples and using S(est), the expected number of species in pooled samples given the reference sample $(189=163$ species for forest, and $291=228$ species for grassland), and showing the upper and lower $95 \%$ confidence limits (dashed lines).

to South Africa or a smaller area within the country, is likely to be an underestimate because for a large proportion of species the level of endemism could not be assessed because of a lack of accessible distribution data. Forty-three species (10\% of the total) are restricted to the Pondoland area and 18 species (4\% of the total) are only known from Mkambati NR. The molluscs have a remarkably high level of endemism, with 43 species (68\%) qualifying as endemic within South Africa, and $47 \%$ of these being restricted to the Pondoland region.

Few invertebrate taxa have been formally assessed according to the International Union for Conservation of Nature (IUCN) Red List criteria (IUCN 2001). The Red List currently includes South African butterflies and Odonata, but none of the species sampled at Mkambati NR are considered as threatened. One mollusc species on the current Red List occurs in Mkambati NR but was not collected during this survey. Natalina beyrichi is categorised as Vulnerable because it has only been collected from Dwessa and Mkambati NRs. The exact locality within Mkambati NR for this species is not known.

\section{Habitats and sites of special concern}

Species presence or absence data for different grassland habitats showed that different habitats were all more than $40 \%$ different (Figure 5a). However, the two sites that were closest to the seashore had similar invertebrate communities (40\% similar), which were distinct from other sites, whereas the rocky ledges also grouped ( $\pm 50 \%$ similar), as did the thick, unburnt grassland sites (Figure $5 \mathrm{a}$ and b). Distance may also be influencing the community structure because sites 16-19 were similar (50\%) (Figure $5 \mathrm{a}$ and b) and were also close in terms of distance between them (Figure 1). These sites were also known to burn at least annually as a result of fires spreading from the adjacent communal areas so fire 
TABLE 1: Summary of number of specimens collected, identified, number of species and number of new species collected for each of the target taxa at Mkambati Nature Reserve.

\begin{tabular}{|c|c|c|c|c|}
\hline Phylum or class & Order & Family or subfamily & $\begin{array}{l}\text { Number of specimens } \\
\text { (no identified) }\end{array}$ & $\begin{array}{l}\text { Number of species } \\
\text { (new species) }\end{array}$ \\
\hline Annelida or Oligochaeta & - & All & $80(41)$ & $3(1-2)$ \\
\hline Mollusca & Gastropoda & All & $479(394)$ & $51(4-9)$ \\
\hline \multirow[t]{3}{*}{ Arthropoda: Arachnida } & Araneae & All & 1275 & $132(5-8)$ \\
\hline & Opilionida & All & 23 & $9(0)$ \\
\hline & Scorpionida & All & 8 & $2(0)$ \\
\hline \multirow[t]{2}{*}{ Arthropoda: Myriapoda } & Chilopoda & All & $58(28)$ & $5(2 ?)$ \\
\hline & Diplopoda & All & $216(100)$ & $11(4-6)$ \\
\hline \multirow[t]{13}{*}{ Arthropoda or Hexapoda } & Odonata & All & $23(18)$ & $8(0)$ \\
\hline & Heteroptera & All & $463(330)$ & $65(2-6)$ \\
\hline & Homoptera & Cicadidae & 8 & $3(0-2)$ \\
\hline & Coleoptera & Carabidae & 18 & $13(0-2)$ \\
\hline & & Cicindellidae & 6 & $2(0)$ \\
\hline & & Cetoninae & 39 & $8(0)$ \\
\hline & & Scarabaeiinae & 24 & $10(0)$ \\
\hline & Neuroptera & All & 10 & $4(0)$ \\
\hline & Lepidoptera & All & $222(190)$ & $32(0)$ \\
\hline & Diptera & Asilidae & $46(45)$ & 11 (?) \\
\hline & & Platystomatidae & 48 & $2(1-2)$ \\
\hline & & Syrphidae & 9 & $6(0-1)$ \\
\hline & Hymenoptera & Apoidea & $275(263)$ & $48(1)$ \\
\hline Total & - & - & 3231 & $425(18-40)$ \\
\hline
\end{tabular}

The number of new species has a range because of taxonomic uncertainties.

TABLE 2: Number of species in different categories of endemism for invertebrate taxa surveyed at Mkambati Nature Reserve.

\begin{tabular}{|c|c|c|c|c|c|}
\hline \multirow[t]{2}{*}{ Invertebrate group } & \multicolumn{4}{|c|}{ Level of endemism $\dagger$} & \multirow[t]{2}{*}{ Total } \\
\hline & National & Regional & Local (multiple localities) & Known from Mkambati only & \\
\hline Araneae & 11 & 15 & 5 & 1 & 36 \\
\hline Opilionida & 6 & 3 & 0 & 0 & 9 \\
\hline Diplopoda & 3 & 2 & 0 & 5 & 10 \\
\hline Mollusca & 11 & 9 & 7 & 8 & 35 \\
\hline Asilidae & 1 & 1 & 0 & 0 & 2 \\
\hline Heteroptera & 0 & 0 & 0 & 2 & 2 \\
\hline Apoidea & 2 & 0 & 0 & 1 & 3 \\
\hline Lepidoptera & 8 & 0 & 0 & 0 & 8 \\
\hline Neuroptera & 1 & 0 & 0 & 0 & 1 \\
\hline Oligochaeta & 0 & 1 & 0 & 1 & 2 \\
\hline Total & 43 & 31 & 12 & 18 & 104 \\
\hline
\end{tabular}

$\dagger$, Levels of Endemism (2002): National = confined to South Africa; regional = confined to an area where the two furthest locality points are less than approximately $330 \mathrm{~km}$ apart, but greater than $60 \mathrm{~km}$ apart (these distances may be slightly larger in this assessment); local = multiple localities and these confined to an area where the two furthest points are less than $60 \mathrm{~km}$ apart (this distance may be slightly larger in this assessment).

frequency may also influence invertebrate diversity. Sites 17 and 18 also had the highest species richness (54 and 55 species) (Figure 2). Site 24 had thick, unburnt grassland with few flowers, and sloped down to a forest patch, and this site was distinct from the other thick, unburned sites (Sites 2, 7,8) that could be explained by its higher altitude (Figure 2).

Species presence or absence data for the different forest types sampled showed that none of the forests were more than $50 \%$ similar if data for all target taxa were used. However, the swamp forest and the swamp or scarp forest had some similarities ( $40 \%$ similar), as did the two scarp forests associated with rivers (50\% similar) (Figure 6a). In the MDS plot, the two swamp forests (sites F11 and F15) are separated from the other forests (Figure 6b). Forest type appeared to be a stronger influence on community structure than distance, with the closest forests not showing the most similar invertebrate community structure.
The forest molluscs were explored further because of the large diversity and the low mobility of this taxon and because it is likely that a high proportion of species present were sampled. Analyses for the molluscs showed similar patterns to those for all taxa, with low levels of similarity in community structure across sites (Figure 7a and b). One swamp forest (F15) was most different from the scarp forests $(<40 \%$ similarity), but this is related to the low number of species (8). The scarp forest on the dunes (F12) was also distinct $( \pm 45 \%$ similarity), and this was related to the high number of species (28), including seven that were unique to this forest.

\section{Discussion}

Information about species' distributions is critical for spatial planning and protected area expansion (Polak et al. 2015), and an understanding of the habitat associations and local distribution patterns of species is essential for local-scale planning and monitoring (Corona et al. 2011). This preliminary 


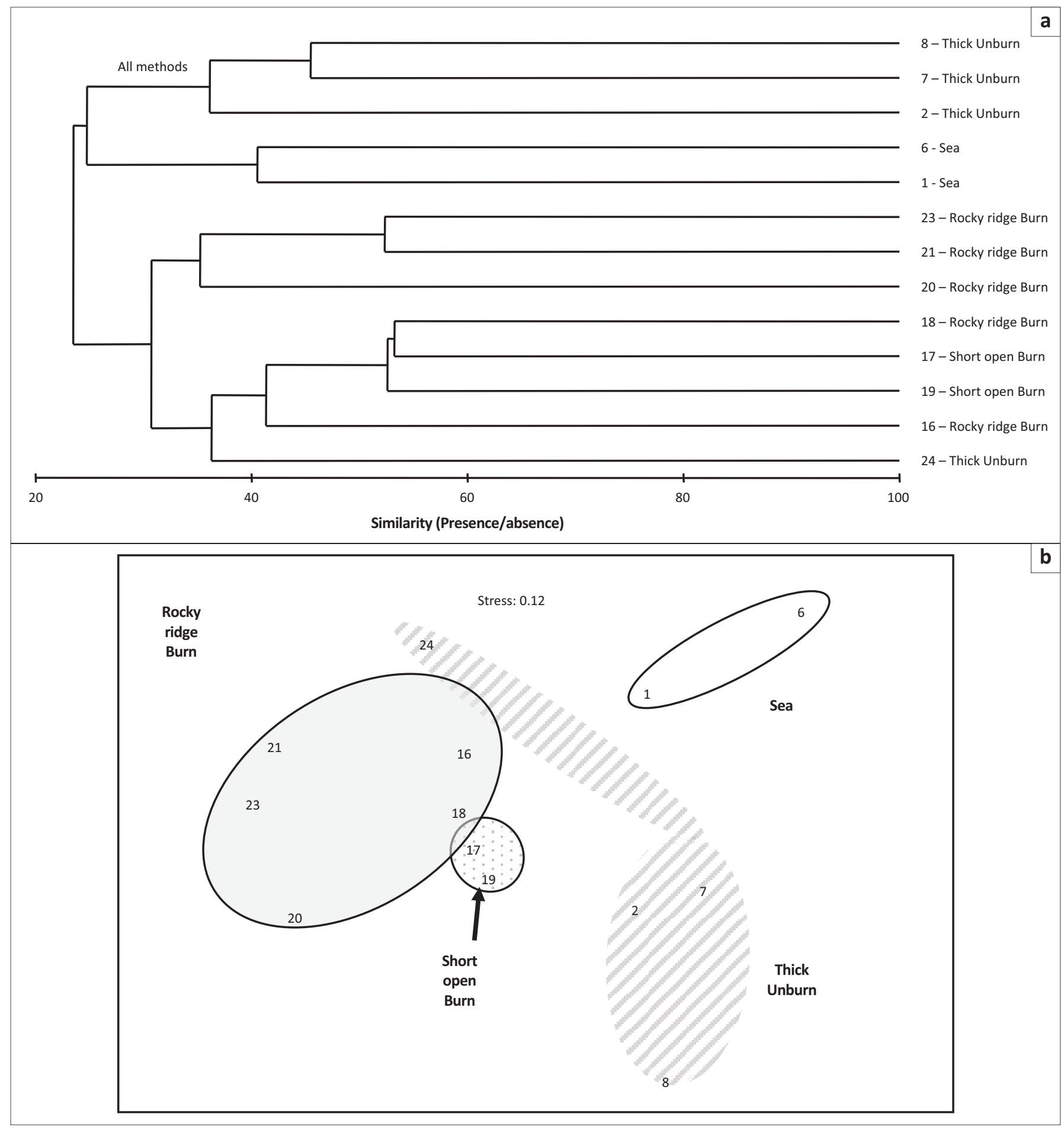

FIGURE 5: Community relationships among grassland sites at Mkambati based on those sites at which all sampling methods were used. (a) Similarity analysis and (b) multi-dimensional scaling analysis.

survey provides new data, which can contribute to understanding the conservation value of Mkambati NR, for planning, development and monitoring within the Reserve. It must be recognised, however, that the survey represents a limited data set in terms of temporal variation and sampling effort, and the estimated species richness is higher than that sampled. Increasing the number of samples collected at each site, as well as the number of sites sampled (Ashcroft et al. 2010), and resampling to capture temporal change would increase the number of species. Increasing sampling effort in invertebrate surveys increases the time and cost of processing and identifying the material (Ward \& Larivière 2004), and these limitations have to be weighed up against the urgent need for data for areas such as those in global biodiversity hotspots. This survey did highlight the high richness, poor knowledge and uniqueness of the invertebrate fauna, and it provides a start in identifying some trends relating to habitats.

The MPA hotspot and the Pondoland Centre of Endemism are recognised as having high plant species richness and 


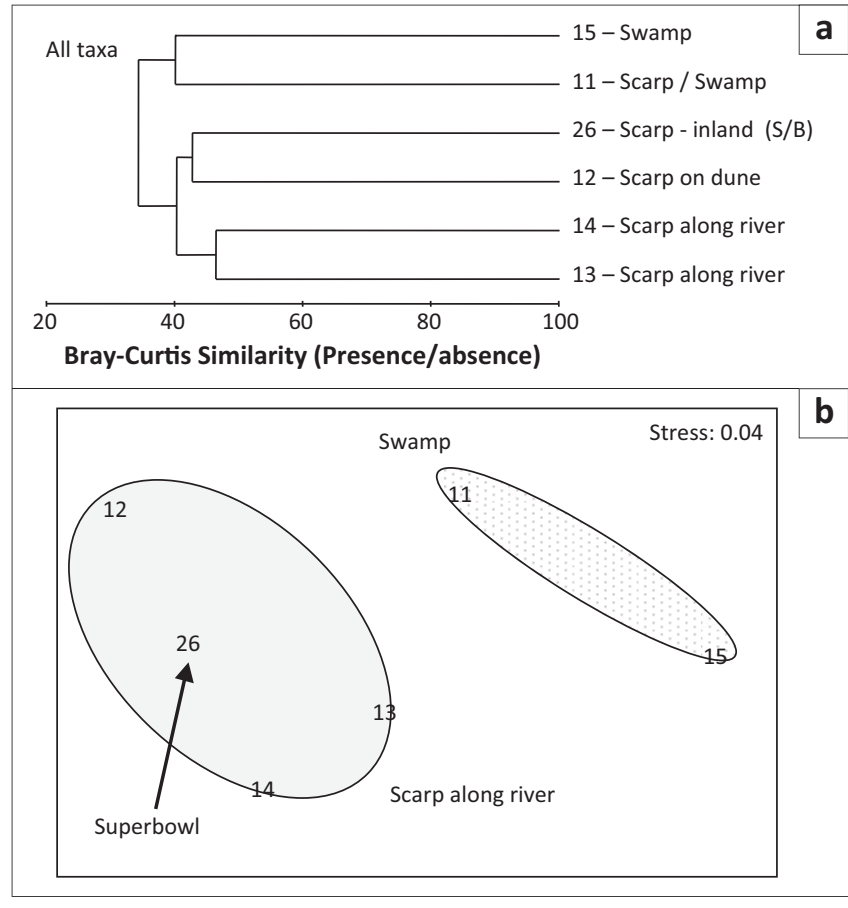

FIGURE 6: Community relationships among forest sites at Mkambati for all taxa. (a) Similarity analysis and (b) multi-dimensional scaling analysis.
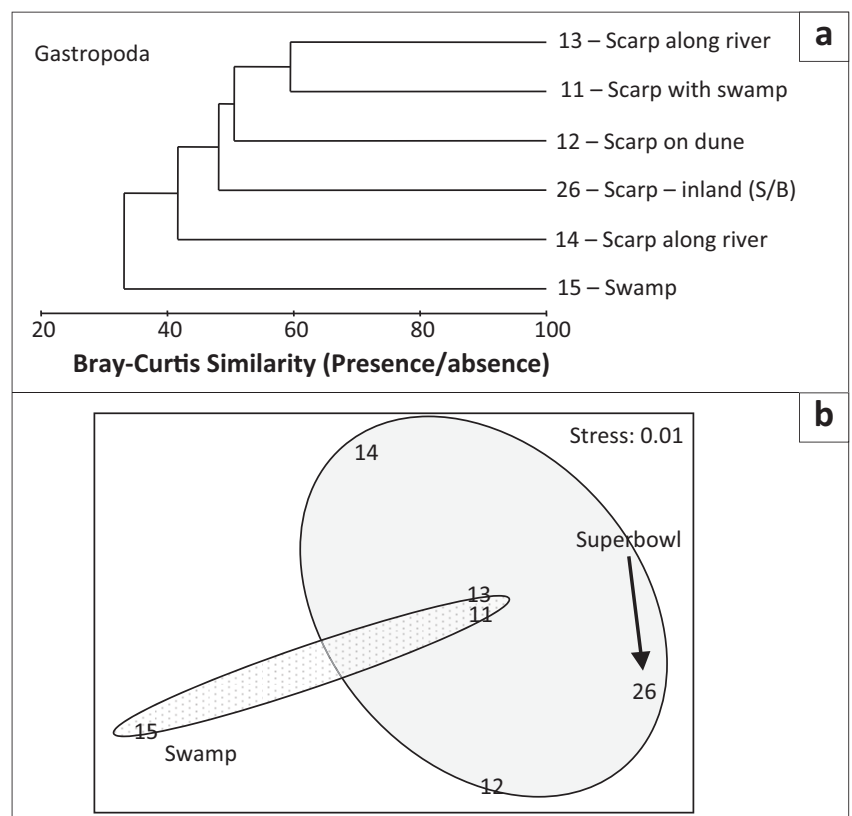

FIGURE 7: Community relationships among forest sites at Mkambati for Mollusca, Gastropoda. (a) Similarity analysis and (b) multi-dimensional scaling analysis.

levels of endemism. Although it is difficult to compare the invertebrate richness of Mkambati NR with that for other localities because of differences in extent of the area surveyed, sampling methods and intensity and taxa included, two other multi-taxa invertebrate surveys within the MPA hotspot do provide at least an indication of the relative richness of the Mkambati NR fauna. A 3-year survey of Mkhuze and Phinda Game Reserves in Maputaland, about $410 \mathrm{~km}^{2}$ in extent, covered 77 sites, most of which were sampled more than once in different seasons or years. A total of 49961 specimens were identified as 716 invertebrate species (Lovell et al. 2010). A survey of 28 forests and 55 grassland sites along the length of the $14740 \mathrm{~km}^{2}$ Maloti-Drakensberg mountains produced 10168 specimens, which yielded 832 species (Hamer \& Slotow 2007). In comparison with these extensive surveys, the 425 species identified from the relatively small $77 \mathrm{~km}^{2}$ area of Mkambati NR suggest exceptional richness. At the level of individual taxa, the number of species sampled at Mkambati NR was also high relative to the Maloti-Drakensberg mountains for some taxa, despite the smaller area and limited sampling effort in the former area. For example, 66 bee species were sampled in the Maloti-Drakensberg survey, 51 species at Mkuze-Phinda and 48 species at Mkambati NR; 48 molluscs were sampled in the Maloti-Drakensberg, 50 in Mkhuze-Phinda and 51 species in Mkambati NR. For the other taxa, the richness was not notably high relative to other areas. For example, the spider richness at Mkambati NR was 132 species (Dippenaar-Schoeman et al. 2011), which is moderate relative to surveys of other protected areas. Haddad and Dippenaar-Schoeman (2009) provided a range of between 76 and 431 species for South African conserved areas for which published surveys exist but none of the reserves they provided data for were in the forest or grassland biome. Millipede and earthworm richness were low relative to Mkhuze-Phinda and the Maloti-Drakensberg mountains, but for both taxa a large number of juvenile specimens were collected and these cannot be identified to species level. The high overall species richness in Mkambati NR is likely to be related to the moderate, stable coastal temperatures relative to those in the high altitude Drakensberg mountains. The biogeography of the fauna needs to be analysed, especially in the context of the flora, which has both palaeoendemics and neoendemics with strong Drakensberg and Fynbos associations (Mucina et al. 2006; Van Wyk \& Smith 2001), but this is beyond the scope of this article.

In addition to species richness, the level of endemism in Mkambati NR is high, with approximately $25 \%$ of species (104) sampled endemic to South Africa. At least 18 of these species are known only from Mkambati NR, and another 12 are local endemics ( $7 \%$ of the total). These percentages are likely to be underestimates because where there was uncertainty about the distribution or identity of a species, this was not included in the count of endemics. Comparison of the values with those for other areas in South Africa is difficult because few published studies have carried out this type of assessment and calculation. The Cape Peninsula, a locality known to have habitats associated with high levels of endemism, was found to have $32 \%$ of invertebrates endemic to that area (Picker \& Samways 1996). The percentage of endemics varied according to taxon with Opilionida having the highest level at $67 \%$ endemic species and the butterflies having the lowest level at 5\%. At Mkambati NR, the molluscs had the highest level of endemism, with 15 species (29\%) that are local endemics or only known from Mkambati NR. Across all taxa, most of the local endemics and those species known only from Mkambati NR are in forests. 
All forests in Mkambati have high conservation value, because all of them, except site F11, produced local endemics or species only known from Mkambati NR that were unique to that forest. Even site F11 had five species that are regional or local endemics, although these were not unique to the forest, and 18 species that were not collected in any of the other forests, although these species are not narrow endemics. Van Wyk and Smith (2001) suggested that swamp forests are small, rare and are impoverished in terms of species and endemics but this does not seem to reflect the situation for invertebrates at Mkambati NR. The Mkambati NR forests illustrate that small forest patches have value for invertebrate conservation; they do not just hold subsets of the species that are present in large forests in the area.

For the grassland biome, rocky ledges should be protected because of their rich and distinct invertebrate fauna, and rocky outcrops were also identified by Perera et al. (2011) as being important for vertebrate endemics. The seashore sites were recognised as being floristically unique by Shackleton et al. (1991), and they are also distinct in terms of their invertebrate community. These habitats are threatened because they cover a limited area and are prime sites for the development of tourist accommodation and facilities. Within the grassland, distance appears to have some effect on community structure, which means that sites prioritised for conservation should cover both altitudinal and latitudinal gradients.

The three richest grassland sites were those that had burnt in spring or early summer and that are known to burn at least annually. It is, however, not possible to draw any conclusions about fire impacts on invertebrates or make any recommendations on fire management based on the limited data.

The large number of gaps in knowledge and the large number of new species collected highlight the need to carry out additional research in the Pondoland region. Additional surveys at different times of the year are important, not only for sampling a different suite of insects, but also for collecting adult males of millipedes and mature specimens of earthworms and spiders. There are many forest patches that remain to be sampled, and given the high levels of uniqueness of the forests that were surveyed, this is likely to increase the species list for the region and the number of new species.

The data collected through this survey, but also through future work, will be useful for planning sustainable development within Mkambati NR, and the trends identified here (high richness and endemism, large differences in communities across forest types and the differences in community even in seemingly similar or homogenous habitats) should also be considered in biodiversity assessments outside the Reserve. We therefore recommend (1) additional surveys, (2) that invertebrate conservation be considered in management and development plans for Mkambati NR and (3) that the results from this study should be considered in the Pondoland area until more robust data for those area have been collected.

\section{Conclusion}

The main objectives of this study were to assess the terrestrial invertebrate fauna in terms of conservation value and to identify habitats and sites of conservation concern in Mkambati NR which falls within the Pondoland Centre of Endemism. A range of sampling methods were used to collect various taxa across 26 sites covering different forest types and grassland habitats. Although far from complete, this survey indicates high species richness especially for bees, true bugs and terrestrial snails, and high levels of endemism. All forests within Mkambati NR have conservation value because of their uniqueness and high number of endemic species. Rocky ridges and the seashore habitats in the grassland had the highest richness and uniqueness, and distance may also influence the similarity of the invertebrate communities in grassland. The results indicate the need for further invertebrate surveys both in Mkambati NR and more widely in Pondoland, and highlight the need to include invertebrates in planning and management of the Reserve.

\section{Acknowledgements}

The authors are very grateful to the following experts for identifying the material collected:

Oligochaeta: Dr Danuta Plisko (KwaZulu-Natal Museum), Molluscs: Prof. Dai Herbert (KwaZulu-Natal Museum), Araneae: Prof. Ansie Dippenaar-Schoeman (ARC), Opilionida: Mr. Leon Lotz (National Museum), Scorpionida: Dr Ian Engelbrecht (private), Neuroptera: Dr Mervyn Mansell (private), Odonata: Dr Tanza Crouch (private), butterflies: Mr Kevin Cockburn (Lepidopterist Society of South Africa), Cetoninae: Prof. Renzo Perissonotto (Nelson Mandela Metropolitan University), Cicindellinae and Carabidae: Dr Peter Schule (private), Scarabaeinae: Dr Adrian Davis (University of Pretoria), Asilidae: Dr Jason Londt (KwaZuluNatal Museum), Syrphidae and Platystomatidae: Dr Andrew Whittington (private), Heteroptera: Dr Dawid Jacobs (University of Pretoria), Cicadidae: Prof. Martin Villet (Rhodes University), and Apoidea: Dr Connal Eardley (ARC). Diplopoda and Chilopoda were identified by the first author.

The authors thank Eastern Cape Parks Board for providing funding and logistical support to carry out this survey. Jan Venter, Dave Balfour and Lwazi Khuzwayo, in particular are thanked for their assistance. The authors thank the Earthwatch volunteers who assisted in the field, as well as University of KwaZulu-Natal (UKZN) technicians Warren Matten, Lynne Stone and Jessica Cockburn. UKZN provided access to a vehicle, and laboratory facilities. Two anonymous experts are thanked for their useful comments on the manuscript. Earthwatch Institute provided funding through the support of British American Tobacco. 


\section{Competing interests}

The authors declare that they have no financial or personal relationships which may have inappropriately influenced them in writing this article.

\section{Authors' contributions}

M.L.H. led the fieldwork, sorting and processing of samples and wrote the manuscript; R.S. assisted with the design of the study and the field sampling, carried out the community analyses and provided input on the manuscript.

\section{References}

Ashcroft, M.B., Gollan, J.R., Faith, D.P., Carter, G.A., Lassau, S.A., Ginn, S.G. et al., 2010 'Using generalised dissimilarity models and many small samples to improve the efficiency of regional and landscape scale invertebrate sampling', Ecological Informatics 5(2), 124-132. https://doi.org/10.1016/j.ecoinf.2009.12.002

Balmford, A. \& Gaston, K., 1999, 'Why biodiversity surveys are good value', Nature 398, 204-205. https://doi.org/10.1038/18339

Cardoso, P., Erwin, T.L., Borges, P.A. \& New, T.R., 2011, 'The seven impediments in invertebrate conservation and how to overcome them', Biological Conservation 144(11), 2647-2655. https://doi.org/10.1016/j.biocon.2011.07.024

Clarke, K.R. \& Gorley, R.N., 2001, Primer v5, Primer-E Ltd, Plymouth, UK.

Clarke, K.R. \& Warwick, R.M., 2001, PRIMER v5: User manual/tutorial, Primer-E Ltd, Plymouth, UK.

Corona, P., Chirici, G., McRoberts, R.E., Winter, S. \& Barbati, A., 2011, 'Contribution of large-scale forest inventories to biodiversity assessment and monitoring', Forest Ecology and Management 262(11), 2061-2069. https://doi.org/10.1016/j. foreco.2011.08.044

Deharveng, L., Bedos, A., Daugeron, C., Villemant, C. \& Judson, M.L., 2015 'Organization, usefulness and limitations of an ATBI (All Taxa Biodiversity Inventory): The inventory of terrestrial invertebrates in the Mercantour National Park', Zoosystema 37(1), 9-30. https://doi.org/10.5252/z2015n1a1

Dippenaar-Schoeman, A.S., Hamer, M. \& Haddad, C.R., 2011, 'Spiders (Arachnida: Araneae) of the vegetation layer of the Mkambati Nature Reserve, Eastern Cape, South Africa', Koedoe 53(1), Art. \#1058, 1-10. https://doi.org/10.4102/koedoe. v53i1.1058

Haddad, C.R. \& Dippenaar-Schoeman, A.S., 2009, 'A checklist of the non-acarine arachnids (Chelicerata: Arachnida) of the De Hoop Nature Reserve, Western Cape Province, South Africa', Koedoe 51, 1-9.

Hamer, M.L., 1999, 'An annotated and illustrated key to the Southern African genera of Spirostreptida (Diplopoda)', Annals of the Natal Museum 40, 1-22.

Hamer, M.L. \& Slotow, R., 2002, 'Conservation application of existing data for South African millipedes', African Entomology 10(1), 29-42.

Hamer, M.L. \& Slotow, R., 2007, 'An assessment and ecological interpretation of the terrestrial invertebrate fauna of the South African portion of the Maloti-Drakensberg bioregion', Unpublished report to the Maloti Drakensberg Transfrontier Project.

Harvey, M.S., 2002, 'Short-range endemism amongst the Australian fauna: Some examples from non-marine environments', Invertebrate Systematics 16(4), 555-570. https://doi.org/10.1071/IS02009

Herbert, D. \& Kilburn, R., 2004, Field guide to the land snails and slugs of eastern South Africa, Natal Museum, Pietermaritzburg.

Hodkinson, I.D. \& Jackson, J.K., 2005, 'Terrestrial and aquatic invertebrates as bioindicators for environmental monitoring, with particular reference to mountain ecosystems', Environmental Management 35(5), 649-666. https://doi.org/10.1007/ s00267-004-0211-x

IUCN, 2001, 2001 categories and criteria, IUCN, Gland, Switzerland, viewed 17 July 2016, from http://www.iucnredlist.org/info/categories_criteria2001

Janzen, D.H., 1973, 'Sweep samples of tropical foliage insects: Effects of seasons, vegetation types, elevation, time of day, and insularity', Ecology 54(3), 687-708. https://doi.org/10.2307/1935359

Kellert, S.R., 1993, 'Values and perceptions of invertebrates', Conservation Biology 7(4), 845-855. https://doi.org/10.1046/j.1523-1739.1993.740845.x

Kepe, T., 2004, 'Land restitution and biodiversity conservation in South Africa: The case of Mkambati, Eastern Cape Province', Canadian Journal of African Studies/La Revue Canadienne des Études Africaines 38(3), 688-704. https://doi.org/10. 2307/4107262
Kepe, T., 2008, 'Land claims and co-management of protected areas in South Africa: Exploring the challenges', Environmental Management 41(3), 311-321. https:// doi.org/10.1007/s00267-007-9034-x

Losey, J.E. \& Vaughan, M., 2006, 'The economic value of the ecosystem services provided by insects', Bioscience 56(4), 311-323. https://doi.org/10.1641/00063568(2006)56[311:TEVOES]2.0.CO;2

Lovell, S.J., Hamer, M.L., Slotow, R.H. \& Herbert, D., 2010, 'Assessment of sampling approaches for a multi-taxa invertebrate survey in a South African savannamosaic ecosystem', Austral Ecology 35, 357-370. https://doi.org/10.1111/j. 1442-9993.2009.02052.x

McGeoch, M.A., Sithole, H., Samways, M.J., Simaika, J.P., Pryke, J.S., Picker, M. et al., 2011, 'Conservation and monitoring of invertebrates in terrestrial protected areas', Koedoe 53(2), Art. \#1000, 1-13. https://doi.org/10.4102/koedoe.v53i2.1000

Mecenero, S., Ball, J.B., Edge, D.A., Hamer, M.L., Henning, G.A., Kruger, M. et al. (eds.), 2013, Conservation assessment of butterflies of South Africa, Lesotho And Swaziland: Red List and atlas, Saftronics (Pty) Ltd, Johannesburg \& The Animal Demography Unit, Cape Town.

Mittermeier, R.A., Robles-Gil, P., Hoffmann, M., Pilgrim, J.D., Brooks, T.B., Mittermeier, C.G. et al. (eds.), 2004, Hotspots revisited: Earth's biologically richest and most endangered terrestrial ecoregions, CEMEX, Mexico, MI.

Moran, V.C., Hoffmann, J.H., Impson, F.A.C. \& Jenkins, J.F.G., 1994, 'Herbivorous insect species in the tree canopy of a relict South African forest', Ecological Entomology 19(2), 147-154. https://doi.org/10.1111/j.1365-2311.1994.tb00404.x

Mucina, L. \& Geldenhuys, C.J., 2006, 'Afrotemperate, subtropical and azonal forests', in L. Mucina \& M.C. Rutherford (eds.), The vegetation of South Africa, Lesotho and Swaziland, pp. 584-614, South African National Biodiversity Institute, and Swazil
Pretoria.

Mucina, L., Scott-Shaw, C.R., Rutherford, M.C., Camp, K.G.T., Matthews, W.S., Powrie, L.W. et al., 2006, 'Indian Ocean coastal belt', in L. Mucina \& M.C. Rutherford (eds.), The vegetation of South Africa, Lesotho and Swaziland, pp. 568-583, South The vegetation of South Africa, Lesotho and
African National Biodiversity Institute, Pretoria.

Myers, N.A., Mittermeier R.A., Mittermeier, C.G., Da Fonseca, G.A.B. \& Kent, J., 2000 , 'Biodiversity hotspots for conservation priorities', Nature 403, 853-858. https:// doi.org/10.1038/35002501

Paoletti, M.G., Thomson, L.J. \& Hoffmann, A.A., 2007, 'Using invertebrate bioindicators to assess agricultural sustainability in Australia: Proposals and current practices', Animal Production Science 47(4), 379-383. https://doi.org/10.1071/EA05288

Perera, S.J., Ratnayake-Perera, D. \& Proches, S., 2011, 'Vertebrate distributions indicate a greater Maputaland-Pondoland-Albany region of endemism', South African Journal of Science 107(7-8), 52-66. https://doi.org/10.4102/sajs.v107i7/ 8.462

Picker, M.D. \& Samways, M.J., 1996, 'Faunal diversity and endemicity of the Cape Peninsula, South Africa - A first assessment', Biodiversity \& Conservation 5(5), 591-606. https://doi.org/10.1007/BF00137611

Polak, T., Watson, J.E.M., Fuller, R.A., Joseph, L.N., Martin, T.G., Possingham, H.P. et al., 2015, 'Efficient expansion of global protected areas requires simultaneous planning for species and ecosystems', Royal Society Open Science 2, 150107 https://doi.org/10.1098/rsos.150107

Prather, C.M., Pelini, S.L., Laws, A., Rivest, E., Woltz, M., Bloch, C.P. et al., 2013 , 'Invertebrates, ecosystem services and climate change', Biological Reviews 88(2), 327-348. https://doi.org/10.1111/brv.12002

Rohr, J.R., Mahan, C.G. \& Kim, K.C., 2006, 'Developing a monitoring program for invertebrates: Guidelines and a case study', Conservation Biology 21, 422-433. https://doi.org/10.1111/j.1523-1739.2006.00578.x

Shackleton, C.M., Granger, J.E., McKenzie, B. \& Mentis, M.T., 1991, 'Multivariate analysis of coastal grasslands at Mkambati Game Reserve, north-eastern Pondoland, Transkei', Bothalia 21(1), 91-107. https://doi.org/10.4102/abc. v21i1.869

Slotow, R. \& Hamer, M., 2000, 'Biodiversity research in South Africa: Comments on current trends and methods', South African Journal of Science 96(5), 222-225.

Tarboton, W. \& Tarboton, M., 2002, A fieldguide to the dragonflies of South Africa, Tarboton \& Tarboton, Modimolle.

Tarboton, W. \& Tarboton, M., 2005, A fieldguide to the damselflies of South Africa, Tarboton \& Tarboton, Modimolle.

Uys, C., Hamer, M. \& Slotow, R., 2010, 'Step process for selecting and testing surrogates and indicators of Afrotemperate forest invertebrate diversity', PLOS One 5(2), e9100. https://doi.org/10.1371/journal.pone.0009100

Van Wyk, A.E. \& Smith, G.F., 2001, Regions of floristic endemism in Southern Africa. A review with emphasis on succulents, Umdaus Press, Pretoria.

Venter, J.A. \& Conradie, W., 2015, 'A checklist of the reptiles and amphibians found in protected areas along the South African Wild Coast, with notes on conservation implications', Koedoe 57(1), Art. \#1247, 1-25. https://doi.org/10.4102/koedoe. v57i1.1247

Ward, D.F. \& Larivière, M.C., 2004, 'Terrestrial invertebrate surveys and rapid biodiversity assessment in New Zealand: Lessons from Australia', New Zealand Journal of Ecology 28, 151-159. 